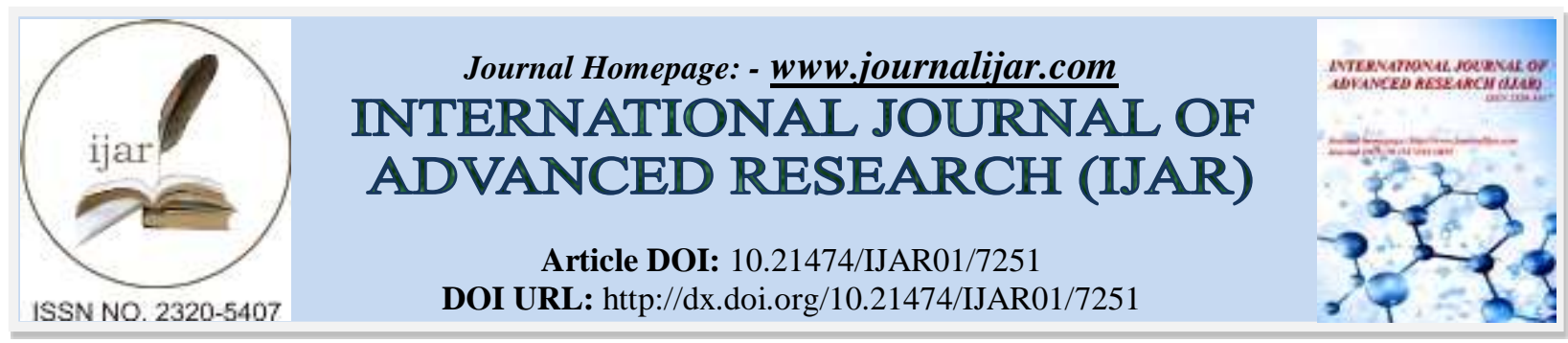

RESEARCH ARTICLE

\title{
PLACENTA PREVIA ACCRETA RISK FACTORS AND PRENATAL DIAGNOSIS BY COLOR.
}

\section{Rasha Rasheed Al Jawhar ${ }^{1}$ and Zeina F. Fuad ${ }^{2}$.}

1. Baghdad Teaching Hospital, Medical City. Baghdad, Iraq.

2. Department of Biochemistry/ University of Diayla.

\section{Manuscript Info}

Manuscript History

Received: 10 April 2018

Final Accepted: 12 May 2018

Published: June 2018

\begin{abstract}
Background: The incidence of placenta accreta has increased dramatically over the last three decades, in concern with the increase in the cesarean delivery rate. Optimal management requires accurate prenatal diagnosis.

Objectives: To identify the risk factors for the development of placenta previa accrete as compared to placenta noneaccrete and to evaluate the role of trans-abdominal color Doppler in diagnosis placenta previa accreta.

Methods: Prospective interventional study done at gynecology and obstetrics department,Baghdad teaching hospital, NursingHome, Medicalcity, Baghdad, Iraq. During the twenty one month study period, 53 woman all beyond 28 week and all with ultrasound diagnosis of placenta previa were included in the study.

Results: Of the 53 placenta previa cases, (ten women exhibited characteristic color Doppler imaging patterns highly specific for placenta accreta. One of them had false positive color Doppler imaging, and nine confirmed at cesarean section to have placenta accreta. Seven of them underwent emergency hysterectomy.

Of the 43 women with negative color Doppler imaging results, two had placenta accreta required cesarean hysterectomy (false negative), and both were posterior placenta previa.

However, there were two cases of placenta previa non accreta required cesarean hysterectomy because of uncontrollable hemorrhage (inertia).

The sensitivity of color Doppler imaging in the diagnosis of placenta previa accreta was $81.8 \%$, specificity was $97.6 \%$, the positive and negative predictive value were $90 \%$ and $95.3 \%$ respectively.

Conclusion: Previous C/S is a major risk factor for the development of placenta accretamainly repeated uterine operation, although both gravidity and curettage increase the incidence they were not reach statistical significance.
\end{abstract}

Copy Right, IJAR, 2018,. All rights reserved.

\section{Introduction:-}

Placenta accreta is a significant cause of maternal morbidity andmortality and is presently the most common reason for emergencypostpartum hysterectomy. It is an abnormal attachment of theplacenta to the myometrium. ${ }^{(1,2)}$

Corresponding Author:- Rasha Rasheed Al Jawhar.

Address:- Baghdad Teaching Hospital, Medical City. Baghdad, Iraq. 
It is estimated that 140000 women die of postpartumhemorrhage per year.Owing to the increasing rate of Cesarean delivery, therehas been a 10 -fold rise in the incidence of placenta accretasince the 1970s. ${ }^{(3)}$

An additional reported risk factors for placenta accreta include maternal age ,multiparity, other prior uterine surgery, prior uterine curettageand uterine irradiation. ${ }^{(4)}$

If Placenta accreta was diagnosed orsuspected before delivery, the optimum time for planneddelivery is around 3435 weeks, following a course of corticosteroidsand multidisciplinary team care approach to avoid possible complications during delivery like massive vaginal bleeding, uterine wall rupture, uterine infection and uterine inversion secondary to attempted manual removal of placenta. ${ }^{(5,6,7,8)}$

Ultrasonography is used routinely for diagnosis of abnormal placentation, although diagnostic criteria and accuracy are still subjectto debate. ${ }^{(9)}$ But color Doppler provide a higher specificity in the diagnosis of placentaaccreta and in particular, the depth of invasion. ${ }^{(10)}$

Traditionally, patients with a prior cesarean delivery and placenta previaare screened for accreta with antenatal sonography, but thedefinitive diagnosis is made postpartum by pathologicdemonstration of chorionic villi invading the myometriumand absence of decidua.

Overall, grayscale sonography is anexcellent tool for the prenatal diagnosis of placenta accreta inwomen at risk for this abnormality. ${ }^{(12)}$ It should bethe primary tool for the diagnosis of placenta accreta andshould be used exclusively in most cases ${ }^{(13)}$

The overallreported sensitivity of MRI is $80 \%$ to $85 \%$ with specificity of $65 \%$ to $100 \%{ }^{(14)}$ It is important to know that when MRI wasused in conjunction with sonography for assessing patientsfor the diagnosis of placenta accreta, MRI was rarely helpfulin changing surgical management. In one study, when MRIdowngraded the sonographic diagnosis, in every case, thepatient still underwent cesarean hysterectomy. ${ }^{(15)}$

\section{Methodology:-}

A prospective clinical study was carried out in Baghdad Teaching Hospital and the Nursing Home from the $1^{\text {st }}$ of July 2014 to 30 of April 2016 on 59 pregnant women with an ultrasound diagnosis of placenta previa.

Women included in this study were beyond 28 weeks gestation, singleton pregnancy and their gestational age were assessed by last menstrual period and/or by U/S performed in the first half of pregnancy.

Those women either attended the hospital directly or they were referred from antenatal care centers, district hospitals, primary health centers and private clinics. Six women were excluded from the study because of lack of follow up. Each women were interviewed personally taking full history, physical and obstetrical examination.

Special attention was paid for the recognized risk factors of placenta accrete.Age, gravidity, parity, number of previous cesarean section ,history of gynecological operation of the uterus (myomectomy or metroplasty) history of curettage,history of APH and significant PPH. gender (sex) of fetus, severe hypotension, rapid pulse, shock, need blood transfusion.

Telephone contact was made to many patients who did not attend antenatal care regularly.The women were scanned with ultrasound real-time equipment utilizing $3.5 \mathrm{MHz}$, phase array transducer (STMENS-SONOLINE ELEGRA).

All women underwent a trans-abdominal B-mode sonography to screen the placental tissue in a systematic fashion, careful attention was paid to homogeneity and echogenicity patterns of the placenta.Then we evaluate the uteroplacental vascular morphological manifestation for every patient with the use of trans-abdominal color Doppler U/S. Sonography was repeated every 2-3 week if possible to see if there is progressive thinning and disappearance of the retro-placental and to exclude any possibility for placental migration. Then the 53 women followed up until delivery to find how the pregnancy ended. We send the patients for investigations like blood group, hemoglobin. The group of women whose showed sign of accreta by Doppler sonography where followed up in the same mentioned route as those of suspected having of pl. pr. without accreta. 
The diagnosis of placenta previa accreta was confirmed at the time of delivery depending on clinical judgment of the surgeon and histopathology when it is appropriate.

The outcome of pregnancy and the maternal morbidity were correlated with the antenatal ultrasonic results of this potentially life- threatening obstetric disorder.Severe bleeding, rupture uterus or injury to the bladder.

\section{Statistical analysis:-}

Data were translated into codes using a specially designed codingsheet, and then entered into a computerized database structure. An expert statistical advice was sought for. Statistical analyses were done using SPSS version 20 computer software (Statistical Package for Social Sciences).

\section{Results:-}

The results presented in this chapter were based on the analysis of 53 pregnant women with an established diagnosis of pl. pr. Those women were followed till delivery to ascertain placenta accreta as an outcome of interest.The age of the study sample ranged between 22-42 years with a median value of 33 years old. The gravidity ranged from 1 and 11 , with a median value of 4 . parity ranged between $0-8$ with a median of 3 , table 1 .

\section{Incidence of placenta accrete:-}

As shown in table 2, the incidence rate of placenta accreta(documented at delivery) among cases of a known diagnosis of pl. pr. was $20.8 \%$ (11 out of 53). The expected incidence rate in the reference population (all possible cases with pl. pr.) would range between 10.8\%-34.1\% with 95\% confidence.

\section{Factors affecting the risk of developing placenta accreta \\ Age}

As shown in table 3, there was no statistically significant differencein the incidence of placenta accretabetween young women $(<35$ years of age inwhich the incidence was $23.3 \%)$ and women 35 years of age and older(incidence was $17.4 \%)$. The slight increase in risk of having placenta accretain the -34-women with an established diagnosis of pl. pr. Those women were followed till delivery to ascertain placenta accreta as an outcome of interest.

Younger age group (1.3 times compared to older group) was not significant statistically. Also there was no significant difference in median age between the group which eventually developed placenta accreta(34 years) and those remaining as previa only (33 years).

\section{Gravidity}

As shown in table 3, the group with higher gravidity (3+) was associated with an obviously higher incidence rate of placenta accreta $(25 \%)$ compared to those with low gravidity $(<3)$ in which none $(0 \%)$ developed placenta accrete.The difference observed however failed to reach the level of statistical significance.

\section{Parity}

As shown in table 3, the group of higher parity (>2 ) had a 1.8 times risk of developing placenta accreta compared to the group with lower parity (1-2). The observed risk together with the difference in incidence rate between the 2 groups was however not significant statistically.

\section{Previous cesarean section}

The incidence of positive history of cesarean section (C/S) in placenta accretagroup was 39.3\%, since none of the cases with a negative history developed placenta accretathis association was statistically significant. The incidence of placenta accretawas significantly associated with the number of previous $\mathrm{C} / \mathrm{S}$, it increased from $31.8 \%$ in those with $1-2$ previous $\mathrm{C} / \mathrm{S}$ to $66.7 \%$ in those with 3 and more $\mathrm{C} / \mathrm{S}$.

\section{History of curettage}

As shown in table 3, a positive history of uterine curettage increased the incidence rate of placenta accretafrom $13.3 \%$ (in those with a negative history) to $30.4 \%$ ). This observed difference and the associated increase risk of 2.3 times failed to reach the level of statistical significance. Although it is not statistically significant, there is positive trend for the effect of increasing of number of previous curettage on the risk of developing placenta accretafrom $13.3 \%$ in those of negative history of curettage to 33.3 in those with curettage done to 3 or more times. 


\section{Association of placenta accreta with selected parameters}

One case $(9.1 \%)$ of placenta previaaccretagroup had history of APH (antepartum hemorrhage), compared to $17(40.5 \%$ )of placenta previa group. On the other hand,PPH (postpartum hemorrhage) as a complication was more frequent in the group of accreta (90.9\%) compared to those remaining as previa (59.5\%). Despite the above, difference did not show a statistical association.

No statistically significant differences were observed in the frequency of the 3 types of delivery (elective, emergency $\mathrm{C} / \mathrm{S}$ and vaginal delivery) between the group which eventually developed placenta accretaand those remaining as previa. Similarly no obvious differences were observed regarding the survival of newborn between the 2 groups. Among the group which eventually developed placenta accrete $9.1 \%$ of newborn had adverse outcome regarding survival and well-being compared to $14.3 \%$ in the other group.

Male gender of the newborn was obviously (although not significant statistically) more frequent among the group which eventually developed placenta accreta $(72.7 \%)$ compared to expected equal proportion observed in the other group (52.4\%), and even in the same group (accreta) male is more incidence than female.

\section{Diagnosis of placenta accreta}

B-mode U/S and color Doppler U/S were both used to diagnose placenta accreta among the 53 cases with established diagnosis of placenta previa. As shown in table 5, 6 and the validity parameters of both U/S diagnostic modalities were compared. Both modalities had similar sensitivity $(81.8 \%)$ and false negative rate (18.2\%), i.e. if $\mathrm{U} / \mathrm{S}$ was to be used as a screening procedure in cases with placenta previa to predict a possible diagnosis of placenta accreta it can detect up to $81.8 \%$ of possible cases with accreta missing (failing to detect) only $18.2 \%$ of cases. The comparability of the 2 modes in sensitivity resulted in almost equal (NPV) negative predictive value (95\%), i.e. U/S can exclude a possible diagnosis of placenta accreta with $95 \%$ confidence in cases with placenta previa.

Color Doppler study had a higher specificity (97.6\%) and therefore higher (PPV) positive predictive value (90\%), i.e. Doppler U/S study can establish the diagnosis of placenta accreta with $90 \%$ confidence among cases with placenta previa. The rate of false positive diagnosis of placenta accreta is obviously higher in B-mode study (7.2\% compared to $2.4 \%$ color Doppler study).In conclusion Doppler U/S study has a higher overall accuracy (94.3\%) in the diagnosis of placenta accreta compared to B-mode U/S study $(90.5 \%)$

\section{Discussion:-}

Clinically important causes of bleeding in thesecond half of pregnancy and in labor includeplacenta previa, placenta accreta, and vasa previa.These conditions are associated with significant maternaland perinatal mortality and morbidity. ${ }^{(16)}$

In this study the maternal age above 35 had no effect on increase the incidence placenta accretathis agree with Morlando et al 2013. ${ }^{(17)}$

But this disagree with Comstock $\mathrm{CH} 2005$ that showed the incidence of placenta accreta should rise steadily over the next century as advanced maternal age ${ }^{(18)}$, this may be explained by small number of patients in our study and the early age of marriage in our country with resultant complete family before 35 years of age .

In agreement with Sofiah S 2009 gravidity was higher in patients with placenta accretahowever it failed to reach statistical significance. This association may reflect the increasing uterine insult with repeated pregnancies ${ }^{(19)}$.

This study fail to show a statistically significant relationship between parity and placenta accreta this agree with Sofiah S 2009 who show that higher parityis not associated with increased incidence of placenta accretaand disagree with Clark SL1999who showed that placenta accretais associated positively with parity. ${ }^{(20)}$ This may be explained that increase parity is not a risk factor but the interference that may occur with deliveries for example we need manual separation of placenta or postpartum curettage that may increase the incidence of accrete rather than parity alone .

This study showed that previous $\mathrm{C} / \mathrm{S}$ is the major risk factor for the placenta accretaand this risk had a significant relationship with number of $\mathrm{C} / \mathrm{S}$ in our study the incidence of placenta accretastarted from $0 \%$ in unscarred uterus to $31.8 \%$ to those with one or two $\mathrm{C} / \mathrm{S}$ up to $66.7 \%$ in those having three or more $\mathrm{C} / \mathrm{S}$. 
This agree with GarimiGali 2012 that show main risk factor for placenta accreta is a previous cesarean delivery and also withNunes Carla et al 2014 that show The incidence of placenta accreta has increased and seems to be parallel to the increasing cesarean deliveryrate. ${ }^{(22)}$

Positive history of curettage and increase number of curettage increased the incidence of placenta accretaand is explained by the facts that repeated curettage increase the chance of endometrialdefect. However it not reach statistical significance.

This agree with Nunes Carla et al 2014 that show The Prior uterine curettage havebeen strongly associated with abnormal placentation. ${ }^{(22)}$

But dis agree with Beuker JM et al 2005 they observe in their study that endomyometrial injury is frequent at termination or dilatation and curettage after miscarriage, but the relation to subsequent placenta accreta remains unclear. $^{(23)}$

In agreement with Oyelese et al 2006 ,history of APH is not statistically significant between pl.pr acc. group and those remaining as previa

This is not the case with PPH as a complication in this study.Severe and serious PPH was significantly more frequent in accrete compared to previa group. ${ }^{(16)}$

In this study fetal outcome regarding preterm birth and neonatal survival showed no statistical significance difference between both group .this agree withBahar A et al 2009 who suggested that the site of placental implantation rather than the degree of placental invasion may be the major determinant of risk of preterm delivery. Placenta previa-accreta is associated with higher maternal morbidity, but similar neonatal outcome compared with patients with an isolated placenta previa. ${ }^{(24,25)}$

In this study fetal male gender was noticed as a risk factor for the development of pl.acc.,although it is statistically not significance this agree with Köstü B et al 2015,but it is un explainable risk factor. ${ }^{(26)}$

Regarding maternal complication fortunatelythere were no maternal death recorded in this study,although it is one of the recorded complication the result of our study agree with Chou et al 2000. ${ }^{(27)}$

Placenta previa-accreta is associated with higher maternal morbidity, this is by Esta I M.et al 2005. ${ }^{(25)}$

Lack of maternal death in our study may be due to multiple reason ;first of all is the small number of the sample ,second ,the study was performed in a tertiary center with ready access to blood bank service, skilled surgeon and intensive care unit .

The antenatal diagnosis of placenta accretaby U/S(B mode and color Doppler)where both having the same sensitivity and NPV(81.8\%\&95\%)respectively .But Doppler U/S had higher specificity and PPV(97.6\%\&90\%)respectively), compared to B mode U/S(92.8\%\&75\%)respectively

In this study the parameter of color Doppler agree with Chou et al $2000,{ }^{(27)}$ and woodringa T C et al 2011 they show that sonography coupled with color-flow Doppler appears helpful in allowing antenatal diagnosis of accreta. ${ }^{(28)}$

In this study, only one case was false positive diagnosed as having placenta accretaby both B mode and color Doppler U/S.this woman admitted at 27 weeks gestation because of repeated attack of vaginal bleeding .the woman had previous two $\mathrm{C} / \mathrm{S}$.Ultrasound showed anterior placenta previa reaching the Os .Both B-mode and Doppler showed no evidence of accrete U/S was repeated every two weeks, and the same result obtained.At 32weeks the patients had several attack of vaginal bleeding that necessitated antenatal blood transfusion .

At $\mathrm{C} / \mathrm{S}$ there was uterine scar dehiscence with placental tissue visible through the scar opining. Removal of the placenta done with delivery of tired preterm baby then repair of the scardone.

Bowman ZS et al 2014 showed that ultrasound for the prediction of placenta accreta may not be as sensitive as previously described. ${ }^{(29)}$ 
Two case were false negatively diagnosed by both modalities (B-mode and Doppler) both had posterior placenta previa and one of them had history of posterior wall myomectomy.

MRI is reported to be the best in evaluation of placenta located posteriorly and in patients with a scar in the posterior wall of the Utters.

In this study four cases of placenta accrete not sent to histopathological study because two case were treated conservatively and the uterus was preserved.The other two cases were not sent because of deficiency of facilities .

\section{Conclusion:-}

Previous $\mathrm{C} / \mathrm{S}$ is a major risk factor for the development of placenta accretamainly repeated uterine operation, although both gravidity and curettage increase the incidence they were not reach statistical significance.

Age and parity were not a risk factor for the development of the placenta accrete.

Intra-partum and postpartum hemorrhage was a major complication of placenta accrete compared to previa alone.

Color Doppler provide an opportunity for early and accurate diagnosis ofplacenta accrete.

\section{Recommendations:-}

Patients at high risk of developing placenta accreta should be extensively examined by color Doppler and properly counseled and to consider performing elective hysterectomy at 34 weeks or even earlier to decrease the incidence of maternal morbidity and mortality.

Uses of the trans-vaginal,trans-labial, trans-rectal sonography and MRI as an altar.

Table 1:- Description of the study sample (cases with placenta previa) by age, gravidity and parity.

\begin{tabular}{|l|l|l|}
\hline & Range & Median \\
\hline Age in years & $(22-42)$ & 33 \\
\hline Gravida & $(1-11)$ & 4 \\
\hline Parity & $(0-8)$ & 3 \\
\hline
\end{tabular}

Table 2:- The incidence rate of pi. acc. (and its 95\% confidence interval) among a study sample of 53 pregnant women with established diagnosis of placenta accreta

\begin{tabular}{|l|l|l|l|}
\hline Placental condition & $\mathbf{N}$ & $\mathbf{\%}$ & 95\% confidence interval \\
\hline Cases with placenta accretadelivery & 11 & 20.8 & $(10.8 \%-34.1 \%)$ \\
\hline Total cases with pl. pr. & $\mathbf{5 3}$ & $\mathbf{1 0 0}$ & \\
\hline
\end{tabular}

Table 3:- The incidence rate of placenta previa acc. by different variables.

\begin{tabular}{|c|c|c|c|c|c|c|c|c|}
\hline \multirow{3}{*}{\multicolumn{2}{|c|}{ Variable }} & \multicolumn{4}{|c|}{ Placental Condition } & \multirow{2}{*}{\multicolumn{2}{|c|}{ TotaL }} & \multirow{3}{*}{$\mathbf{P}\left(\mathbf{X}^{2}\right)$} \\
\hline & & \multicolumn{2}{|c|}{ Previa } & \multicolumn{2}{|c|}{ accreta } & & & \\
\hline & & $\mathbf{N}$ & $\%$ & $\mathbf{N}$ & $\%$ & $\mathbf{N}$ & $\%$ & \\
\hline \multirow{2}{*}{ Age } & $<35$ & 23 & 76.7 & 7 & 23.3 & 30 & 100 & \multirow{2}{*}{0.48} \\
\hline & $35+$ & 19 & 82.6 & 4 & 17.4 & 23 & 100 & \\
\hline \multirow{2}{*}{ Gravida } & $<3$ & 9 & 90 & 0 & 0 & 9 & 100 & \multirow{2}{*}{0.35} \\
\hline & $3+$ & 33 & 75 & 11 & 25 & 44 & 100 & \\
\hline \multirow{2}{*}{ parity } & $<2$ & 13 & 86.7 & 2 & 13.3 & 15 & 100 & \multirow{2}{*}{0.99} \\
\hline & $2+$ & 29 & 67.3 & 9 & 23.7 & 38 & 100 & \\
\hline \multirow{3}{*}{$\begin{array}{l}\text { Previous } \\
\text { C/S }\end{array}$} & Non & 25 & 100 & 0 & 0 & 25 & 100 & \multirow{3}{*}{$\begin{array}{l}<0.001 \\
\text { Sig. }\end{array}$} \\
\hline & $1-2$ & 17 & 68.2 & 7 & 31.8 & 22 & 100 & \\
\hline & $3+$ & 2 & 33.3 & 4 & 66.7 & 6 & 100 & \\
\hline \multirow{3}{*}{ Previous curettage } & Non & 26 & 86.7 & 4 & 13.3 & 30 & 100 & \multirow{3}{*}{0.15} \\
\hline & $1-2$ & 12 & 70.6 & 5 & 29.4 & 17 & 100 & \\
\hline & $2+$ & 4 & 66.7 & 2 & 33.3 & 6 & 100 & \\
\hline
\end{tabular}


Table 4:- Difference in rate of selected variable between patients ending with palacenta accreta and those remaining as aprevia

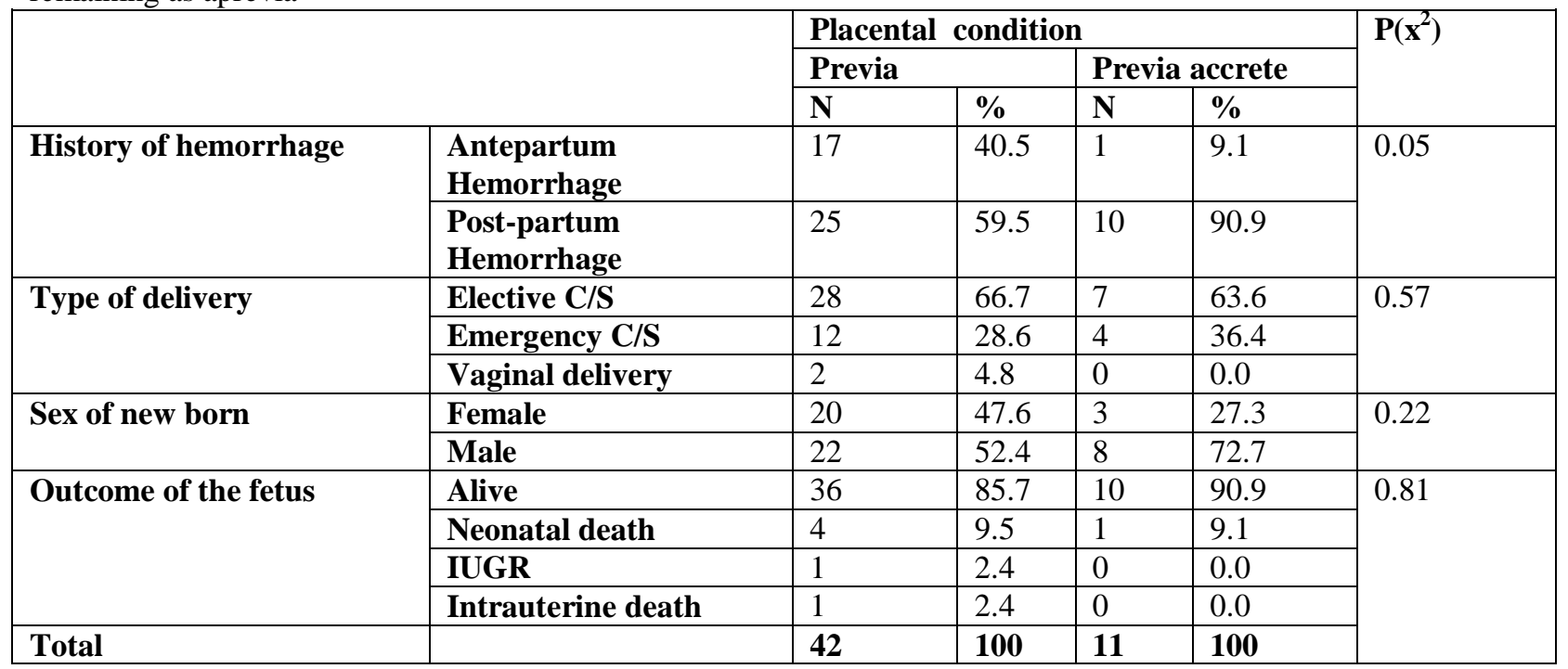

Table 5:-Validity parameter of B-mode U/S diagnosis of placenta previa accreta among 53 cases with placenta previa

\begin{tabular}{|l|l|l|l|l|}
\hline $\begin{array}{l}\text { Placentaaccreta } \\
\text { diagnosed B- } \\
\text { mode U/S study }\end{array}$ & Placental condition & Total & $\begin{array}{l}\text { Sensivity =81.8\% } \\
\text { Specifity=92.8\% } \\
\text { PPV }=75 \%\end{array}$ \\
\cline { 2 - 4 } Nagative & Previa & Accreta & & NPV =95.1\% \\
\hline Positiv & 39 & 2 & $\mathbf{4 1}$ & False+ ve =7.2\% \\
\hline Total & 3 & 9 & $\mathbf{1 2}$ & $\begin{array}{l}\text { False-ve }=18.2 \% \\
\text { Accuracy }=90.5 \%\end{array}$ \\
\hline
\end{tabular}

Table 6: Validity parameter of Doppler U/S diagnosis of placenta previa accreta among 53 cases with placenta previa

\begin{tabular}{|l|l|l|l|l|}
\hline $\begin{array}{l}\text { Placenta accreta } \\
\text { diagnosed } \\
\text { byDoppler U/S } \\
\text { study }\end{array}$ & Placental condition & Total & $\begin{array}{l}\text { Sen.=81.8\% } \\
\text { Spec. =97.6\% } \\
\text { PPV }=90 \%\end{array}$ \\
Negative & Previa & & & Accreta $=95.3 \%$ \\
\hline Positive & 41 & & & False+ ve=2.4\% \\
\hline Total & 1 & 2 & $\mathbf{4 3}$ & False-ve $=18.2 \%$ \\
Accuracy=94.3\%
\end{tabular}

Table 7:- Frequency distribution of cases with an established diagnosis of placenta previa accreta by method of establishing the diagnosis.

\begin{tabular}{|l|l|l|}
\hline $\begin{array}{l}\text { Method of establishing the diagnosis of placenta } \\
\text { accreta }\end{array}$ & $\mathrm{N}$ & $\%$ \\
\hline Clinical and histopathology & 7 & 63.6 \\
\hline Clinical (observation) & 4 & 36.4 \\
\hline Total & $\mathbf{1 1}$ & $\mathbf{1 0 0}$ \\
\hline
\end{tabular}

\section{References:-}

1. Riteau A-S, Tassin M, Chambon G, Le Vaillant C, de Laveaucoupet J, et al. Accuracy of Ultrasonography and Magnetic Resonance Imaging in the Diagnosis of Placenta Accreta. PLoS ONE.2014;9(4).

2. Dwyer B K, Victoria Belogolovkin V, Tran L, Rao A, Carroll I, BarthR, ChitkaraU.Prenatal Diagnosis of Placenta Accreta Sonography or Magnetic Resonance Imaging?J Ultrasound Med 2008; 27:1275-1281. 
3. Shih J C, Jaraquemada J M P, Shyu M K, Lin S Y, and Lee C N.Role of three-dimensional power Doppler in the antenatal diagnosis of placenta accreta: comparison with gray-scale and color Doppler techniques.Ultrasound ObstetGynecol 2009; 33: 193-203.

4. Fitzpatrick K E, Sellers S, Spark P, Kurinczuk J J, Brocklehurst P and Knight . Incidence and Risk Factors for Placenta Accreta/Increta/ Percreta in the UK: A National Case-Control Study.Plose one,December 2012; $7: 12$.

5. Birnbach DJ, Browne IM. Anesthesia for Obstetrics. Chapter 69. In: Miller's Anesthesia. 7th edition. Saunders; 2009.

6. Abuhamad A. Morbidly adherent placenta. SeminPerinatol 2014; 37; 359-64.

7. Oyelese Y, Smulian JC. Placenta previa, placenta accreta, and vasa previa. ObstetGynecol 2006; 107: 927-41

8. Eshkoli T, Weintraub AY, Sergienko R, Sheiner E. Placenta accreta: risk factors, perinatal outcomes and consequences for subsequent births. Am J ObstetGynecol 2013; 208: 219.

9. Cali G, Giambanco L, Puccio G and Forlani F.Morbidly adherent placenta: evaluation of ultrasound diagnostic criteria and differentiation of placenta accrete from percreta.Ultrasound ObstetGynecol 2013; 41: 406-412.

10. Cheung C S and Chan B C. The sonographic appearance and obstetric management of placenta accrete. International Journal of Women's Health 2012:4 587-594.

11. Berkley E M and Abuhamad A Z.Prenatal Diagnosis of Placenta Accreta Is Sonography All We Need?J Ultrasound Med 2013; 32:1345-1350. |

12. American College of Obstetricians and Gynecologists. Placenta accreta: committee opinion no. 529. ObstetGynecol 2012; 120:207-211.

13. Esakoff TF, Sparks TN, Kaimal AJ, et al. Diagnosis and morbidity of placenta accreta. Ultrasound ObstetGynecol 2011; 37:324-327.

14. Gielchinsky Y, Mankuta D, Rojansky N, Laufer N, Gielchinsky I, Ezra Y. Perinatal outcome of pregnancies complicated by placenta accreta. ObstetGynecol 2004; 104:527-530.

15. McLean LA, Heilbrun ME, Eller AG, Kennedy AM, Woodward PJ. Assessing the role of magnetic resonance imaging in the management of gravid patients at risk for placenta accreta. AcadRadiol 2011; 18:1175-1180.

16. OyeleseYandSmulian J C.Placenta Previa, Placenta Accreta, and Vasa Previa.American collage of obstetric and gyengology .2006; 107:. 4.

17. Morlando M, Sarnos L, Napolitano R, Capone A,Tessitoret G, Maruotti G M\&Martinelli P.Placenta accreta: incidence and risk factors in an area with a particularly high rate of cesarean section.Nordic Federation of Societies of Obstetrics and Gynecology .2013; 457-460.

18. Comstock CH. Antenatal diagnosis of placenta accreta: a review. Ultrasound ObstetGynecol 2005; 26:89-96.

19. Sofiah S and Fung LYC.Placenta Accreta: Clinical Risk Factors, Accuracy ofAntenatal Diagnosis and Effect on Pregnancy Outcome.Med J Malaysia .2009; 64: 4.

20. Clark SL.Placenta previa and Abruptio placentae.CreasyRK,ResnikR.Maternal fetal medicine $.4^{\text {th }}$ ed .Philadelphia.W.B.Saunders Company .1999;616-621.

21. GarimiGali ,RaedSalim Epidemiology, Etiology, Diagnosis, and Management of Placenta Accreta.Obstetrics and Gynecology International.2012; 7

22. Nunes C, CarvalhoR.M.Araújo C, SantoS and Melo A.Diagnosis of placenta accreta by ultrasonography: a "gold standard. ActaObstetGinecol Port 2014;8(2):136-140.

23. Beuker $\mathbf{J}$ M, Erwich $\mathbf{J} \mathbf{J}$ HM and KhongT Y.Is endomyometrial injury during termination of pregnancy or curettage following miscarriage the precursor to placenta accreta?J ClinPathol 2005; 58:273-275.

24. Bahar A, Abusham A, Eskandar M Sobande A and Alsunaidi M.Risk Factors and Pregnancy Outcome in Different Types of Placenta Previa.J ObstetGynaecol Can 2009; 31(2):126-131.

25. Usta I M ,Hobeika E M, Abu Musa A A,, Gabrie G E and NassarA H . Placenta previa-accreta: Risk factors and complications.americangournal of obstetric and gyencolgy . 2005; 193: 1045-1049.

26. Köstü1 B, Ercan O, Özer A, Bakacak M and Avc F.Male fetus domination in total placenta previa cases.Perinatal Journal 2015;23(2):84-88.

27. Chou MM,HoES,LeeYH.Prenatal diagnosis of placenta previa accreta by transabdominal color Doppler .U/S Obstet .Gynecol .2000;15:28-35.

28. Woodringa T C, Klauserb C K, Bofilla J A, Martina R W \& Morrison J C.Prediction of placenta accreta by ultrasonography and color doppler imaging. The Journal of Maternal-Fetal \& Neonatal Medicine.2011; 24: $1,118-121$.

29. Bowman ZS, Eller AG, Kennedy AM, Richards DS, Winter TC, Woodward and Silver RM.Accuracy of ultrasound for the prediction of placenta accreta.Am J Obstet Gynecol. 2014 Aug; 211(2):177. 